\title{
ÁREA CENTRAL DE TERESINA (PI): INTERVENÇÕES URBANAS, AGENTES E PROCESSOS
}

\author{
Silvana de Sousa Silva \\ Mestre em Geografia - Universidade Federal do Piauí \\ syllsousa@hotmail.com \\ Antonio Cardoso Façanha \\ Programa de Pós-Graduação em Geografia da - Universidade Federal do Piauí \\ facanha@ufpi.edu.br
}

\begin{abstract}
Resumo
As dinâmicas que integram as áreas centrais das cidades concorrem para a configuração de processos que frequentemente demandam intervenções, orientadas para a promoção de reorganizações espaciais. Diante das considerações, objetivou-se analisar as intervenções efetivadas na área central de Teresina (PI) a partir do plano diretor-Agenda 2015, e o papel exercido para a dinâmica das ações dos agentes e atividades desenvolvidas. Os procedimentos metodológicos foram compostos pela revisão de referencial teórico, aplicação de questionários em formulários, tabulação e análise de dados, registros fotográficos e elaboração de mapas. Conclui-se, que ao considerar as intervenções oriundas dos projetos da Agenda 2015 para a área central de Teresina, foi possível verificar que os principais agentes envolvidos apresentaram atuação diferenciada contribuindo para a constituição de resultados diversos e a reprodução de desafios.
\end{abstract}

Palavras-chave: Área central. Intervenções urbanas. Agentes produtores. Teresina (PI).

\section{CENTRAL AREA TERESINA (PI): INTERVENTIONS URBANS, AGENTS AND PROCESSES}

\begin{abstract}
The dynamics that make up the central areas of cities compete for configuring processes that often require interventions aimed at promoting spatial reorganizations. On the considerations aimed to analyze the intervention effect in the central area of Teresina (PI) from director plan, Agenda 2015 and the role played in the dynamics of the actions of agents developed and activities. The methodological procedures were composed by theoretical review, questionnaires forms, tabulation and data analysis, photographic records and preparation of maps. It is concluded that when considering interventions coming from the Agenda 2015 project to the central area of Teresina, we found that the key players involved had different activities contributing to the creation of many results and playing challenges.
\end{abstract}

Keywords: Downtown area. Urban interventions. Producing agents. Teresina (PI). 


\section{Introdução}

O processo de reprodução das relações no/do espaço urbano, revela um conjunto de dinâmicas espaciais que auxiliam na análise da configuração de alterações nos usos dos espaços e das formas, reproduzidos para o atendimento de objetivos distintos. Dessa forma os debates que envolvem a compreensão dos processos em escala local perpassam a caracterização de recortes espaço-temporais, que convergem para o enfoque do objeto em análise.

Nesse momento, ganha relevo a abordagem das especificidades que integram a área central e a centralidade desempenhada pelo conjunto de atividades socioeconômicas, que caracterizam esse recorte espacial. Diante das observações, objetivou-se analisar as intervenções efetivadas na área central de Teresina (PI) a partir do plano diretor-Agenda 2015, e o papel exercido para a dinâmica das ações dos agentes e atividades desenvolvidas.

Para tanto, os procedimentos metodológicos foram compostos pela revisão de referencial teórico com ênfase para autores que abordaram a dinâmica do espaço urbano, planejamento, planos diretores e intervenções urbanas. Somam-se ainda a aplicação de 14 questionários em formulários com lojistas, 92 com os ambulantes que atuavam nas ruas da área central, antes das intervenções e entrevistas com representantes da Associação dos Vendedores do Comércio Informal (AMESCI) e da Prefeitura Municipal de Teresina (PMT), os dados foram tabulados e associados às discussões teóricas, aos registros fotográficos e à produção de mapas para espacialização dos processos estudados.

\section{Centro e Centralidade Urbana: processos da/na área central}

O estudo dos processos de (re)produção no espaço urbano, permite a constatação da coexistência de propriedades diversas, podendo-se destacar a centralização de funções ou processos em determinados recortes, na conjuntura temporal considerada. Porém, ressalta-se que elas não são fixas e frequentemente encontram modificações, como a formação de descentralizações de funções, que refletem as implicações da dinâmica das relações sócioespaciais.

Os debates para caracterização da área central, sob a ótica da Geografia são subsidiados pelas análises de Corrêa (2005, p.124), ao afirmar que "[...] do ponto de vista do capital, a área central constituía na segunda metade do século XX e ainda hoje, para muitas atividades uma localização ótima, racional, que permitiria uma maximização dos lucros”. Ou seja, a 
partir da (re)produção continuada que se processa nas cidades, esse espaço ainda pode atrair atividades como àquelas que pertencem ao setor terciário.

$\mathrm{Na}$ abordagem do papel das áreas centrais Spósito (2013) defende que no processo de estruturação do espaço urbano a redefinição dos papeis desempenhado por esse recorte assume importante papel. Nesse processo ganham destaque o a centralidade exercida em larga escala pela área central, mas também a dispersão que concorreu para a constituição de novas centralidades.

Nesse momento, o aprimoramento das assimilações é mediado pelos levantamentos das dinâmicas de formação dos espaços. Assim, Villaça (2001, p. 238) defende que para compreensão da centralidade é necessário destacar que “[...] nenhuma área é ou não é centro; como fruto de um processo - movimento - torna-se centro. [...]".

Depreende-se, portanto que o resgate das iniciativas que concorreram para a origem de determinada área central, exerce papel de subsídio para a necessidade de observações que possibilitam a identificação dos processos canalizados para a constituição da área central, como ferramenta para a compreensão das dinâmicas atuais.

Auxiliando essa tarefa, o autor em destaque relaciona as ideias de aglomeração e cooperação, ressaltando que o desenvolvimento desses processos é acompanhado pelo afastamento, na medida em que não é possível a formação de uma aglomeração concentrada em um ponto único. Essa dispersão gera também espaços vazios onde antes predominavam relações sustentadas pela capacidade de aglomerar, além disso, observa-se que o mercado ganha notoriedade.

Essas dimensões constitutivas oportunizam o reconhecimento de papéis desempenhados pela área central, considerando as possibilidades que podem ser trabalhadas. Essa perspectiva atua objetivando a construção de entendimento da produção. Ademais, como observa Silva (2005), a análise do Centro permite a identificação de dinâmicas espaço-temporais diferenciadas.

A coexistência de perfis diferenciados é reforçada por Tourinho (2006, p. 280), ao ressaltar que o Centro como metonímia da cidade contém “[...] as identidades das lutas, fracassadas ou vitoriosas, assim como dos esforços, legítimos ou ilegítimos, realizados por vários "modelos de sociedade" que já viveram, ou ainda vivem, na cidade atual [...]”.

Logo, verifica-se que as características constatadas na área central, permanecem durante períodos vivenciados no urbano, estando associadas à produção de atividades dos agentes, que 
Silvana de Sousa Silva; Antonio Cardoso Façanha

deliberam nesse recorte. Essa dinâmica propicia o reconhecimento de processos desenvolvidos nos demais espaços da cidade, respaldado por elementos que imprimem singularidades.

As modificações resultantes da dinamicidade nas cidades, permitem o reconhecimento de alterações no significado da área central. Nesse contexto, recebe destaque a inserção de novos usuários compreendidos especialmente pelos integrantes de baixa renda, conjugados à existência de transporte coletivo, facilitador de deslocamento envolvendo a passagem pelo Centro, nesse sistema as praças funcionam como terminais de ônibus. O Centro passa a vivenciar uma redefinição quando considerada a estrutura urbana, porém esse processo não é acompanhado pelo abandono da totalidade das atividades, até então hegemônicas (DANTAS, 1997).

Do enunciado, são efetivados desdobramentos como expresso por Dantas (1997), ao afirmar que esse curso leva a modificações na articulação entre as diferentes partes da cidade e o Centro, que passa a vivenciar conflitos por causa da inserção de outros usuários, cujas funções não correspondem àquelas que representam papel preponderante anteriormente.

Os apontamentos possibilitam a assimilação de características, adquiridas pelos encaminhamentos que se efetivam na dinâmica de (re)produção das relações sócio-espaciais da área central. No entanto, as observações na área central demonstram a heterogeneidade de objetivos além de questões relacionadas a modificações na centralidade, mas também a permanência de atividades que embora tenham iniciado a descentralização, ainda mantêm localização na área central, associados às características das formas, processos e agentes nesse recorte.

Percebe-se dessa forma, a coexistência de processos na formação das áreas centrais das cidades, juntamente com as conjunturas de inter-relações desiguais que são identificáveis, incorporadas aos conteúdos dos debates. Esses aspectos contribuem para o reconhecimento da relevância de análises que integram a abordagem dos fatos que envolvem a formação, mas também a dinâmica da ação dos agentes, das formas e das funções correspondentes aos resultados subsidiados pela dinâmica dos processos, além da atuação dos instrumentos para planejamento urbano.

\section{Planejamento Urbano, Plano Diretor e Planejamento Estratégico}


A análise do conjunto de processos que integram a dinâmica do espaço urbano, entre eles a configuração do Centro e da centralidade em diferentes escalas, demanda a abordagem das características que compõem as orientações para o planejamento urbano, plano diretor e a investigação da constituição de planejamentos estratégicos que priorizam as relações de mercado.

O planejamento urbano, conforme as observações de Souza (2006) corresponderia a uma ação que dispõe sobre o futuro, para tanto tenta prever as características evolutivas de um dado fenômeno ou um conjunto destes, visando conhecer os possíveis desdobramentos de um processo, para identificar os problemas ou ainda aproveitar os benefícios resultantes dessa evolução.

$\mathrm{Na}$ discussão do planejamento, Souza e Rodrigues (2004) ressaltam que entre os desafios gerados por essa atividade, está a exigência da efetivação de reflexões e análises, ligadas às situações que podem ser verificadas atualmente. Essa prática produz subsídios para o levantamento e compreensão das possibilidades que se configurarão, representando alterações nas ações de prognóstico.

Diante desse quadro, Souza e Rodrigues (2004) defendem que o desafio que se impõe corresponde ao trabalho de realização de prognósticos contemplando os processos que se desdobram ao longo da história, abordando-a como um processo aberto que, por conseguinte desperta para múltiplas possibilidades.

No entanto, quando se discute a atuação do papel do planejamento, algumas contradições são reveladas e em muitos momentos, são foco de críticas que defendem a necessidade de observações detalhadas para que o processo possa envolver qualidades previamente pensadas, possibilitando maior atribuição de significado a cada etapa que integra o processo. Recebem importância nessa análise, a ampliação diferenciada da participação dos agentes sociais e as características efetivamente realizadas, além de acompanhamento do processo de elaboração.

$\mathrm{Na}$ composição dos instrumentos, para planejamento urbano no Brasil, assumem importância as caraterísticas do Estatuto das Cidades e as atribuições das características do Plano Diretor que deveria ser aprovado através de Lei para municípios com mais de 20.000 habitantes; àqueles que compõem regiões metropolitanas; que correspondam à área com interesse turístico; áreas que recebem influência de empreendimentos que oferecem riscos de 
Silvana de Sousa Silva; Antonio Cardoso Façanha

impactos ambientais e municípios com áreas que tem possibilidades de deslizamentos, inundações, dinâmicas geológicas ou hidrológicas com grandes proporções (BRASIL, 2001a).

Apresentando considerações sobre o Plano Diretor, Souza (2006) defende que estes não precisam ser rígidos ou totalmente detalhados pretendendo a construção da cidade ideal. Os planos devem ser reflexos das metas e prioridades, fornecendo instrumentos adequados à realidade de uma cidade, entendida a partir das necessidades reais. Complementando as afirmações, Lacerda et al. (2005) defende que o plano deve possuir interface com os outros instrumentos, orientados para o planejamento no âmbito da administração municipal, ademais as proposições devem ressaltar os limites e possibilidades para intervenções.

No âmbito da Reforma Urbana inserida nos debates da constituinte de 1988, Maricato (2012) observa que o Plano Diretor foi rejeitado pelas entidades que assinaram a Emenda Popular pela Reforma, na medida em que esses planos no Brasil possuíam trajetória marcada pela aprovação dos projetos, propostos pelas elites e expulsão dos pobres de áreas valorizadas. No entanto, o Plano Diretor permaneceu revelando dessa forma as desigualdades na concretização das decisões.

Descrevendo uma síntese do cenário urbano brasileiro, relacionado aos contextos de constituição e aplicação dos planos diretores, Ultramari e Rezende (2008) destacam que os planos devem considerar aspectos como o aumento da complexidade das questões urbanoambientais e redução no quadro de servidores públicos, demandando empresas de consultoria, responsáveis pela elaboração dos planos, fato que representa dificuldades para a continuidade das ações.

Segundo os autores, durante a construção do Plano Diretor, deve ser discutido a constituição de um sistema para o acompanhamento e controle das ações previstas para implementação, no recorte temporal delimitado. Esse sistema deverá examinar também as intervenções efetivadas. O plano deveria abordar ainda, exigências voltadas para o âmbito dos municípios que possuem áreas de riscos de deslizamento e para àquelas que visam promover ampliações no perímetro urbano, pois devem obedecer a regras específicas para o ordenamento dos espaços da cidade.

Partindo das colocações, ressalta-se que um número diversificado de atribuições é imposto como integrante de um Plano Diretor, que contém deliberações para a (re)produção espacial. Porém, essa dinamicidade pode não ser contemplada efetivamente, diante da 
complexidade que envolve as relações que estão inseridas no universo da produção dos planos, execução de projetos e gestão das ações.

Ademais, frequentemente, tem-se observado a adoção de planos que não assumem as características demandadas pelos planos diretores, predominando as estratégias que associam as cidades ao funcionamento de empresas.

Nas ações para planejamento, pode-se verificar que uma reunião de propostas foi organizada ao longo dos anos, tendo em vista o atendimento das metas estabelecidas para um determinado período, segundo as características que se configuram. Nesse cenário, torna-se relevante o desenvolvimento de observações que englobam os processos contidos, na elaboração dos planos diretores.

O agrupamento de um conjunto diversificado de critérios, associado às peculiaridades que compõem os planos, permite o levantamento de informações relevantes para a compreensão das orientações que subsidiam o planejamento, em diferentes momentos.

As modificações que se processam na conjuntura das relações sob a ótica do capital, instigam os debates que envolvem a dinâmica das ações para intervenções, projetadas para os espaços das cidades. Nessa perspectiva, Castells e Borja (1996, p.52) defendem que as cidades podem ser apreendidas como "[...] atores sociais complexos e de múltiplas dimensões".

Compondo fundamentos para o Planejamento Estratégico, os autores observam que os resultados eficazes dos planos, estão relacionados a definição de um projeto de futuro que mobilize setores públicos e privados em torno de ações, com implementação imediata. Essa ação se torna fundamental para a construção de confiança entre agentes, estabelecendo consensos. Assim o plano deve edificar e/ou transformar a imagem da cidade e suas projeções, envolvendo os cidadãos para mobilizá-los. Além disso, o plano precisa de uma reforma política como ação elementar, pois é realizado o questionamento do governo local considerando organização, competência e inter-relação com as outras esferas administrativas.

Considerando os planejamentos estratégicos Ultramari e Rezende (2008, p.11) observam a "[...] necessidade de criar consenso sobre um modelo de futuro da cidade, segundo a percepção de mudanças em curso, de dar respostas às crises, à recessão dos setores básicos da economia e também de perseguir maior coesão e integração territorial. [...]”.

As características assumidas por esse plano demonstram a busca pela transferência dos conceitos presentes na dinâmica organizacional empresarial, como exercício que possibilitaria 


\section{Silvana de Sousa Silva; Antonio Cardoso Façanha}

a configuração de um conteúdo de destaque para a cidade. No entanto, a compreensão dos papéis assumidos pelos agentes de produção, formas e funções que coexistem, demonstra que um grupo atento de observações deve ser construído.

Complementado as observações, Vainner (2000) evidencia uma crítica das ações para o planejamento estratégico, observando as ideologias. No primeiro momento, a cidade é percebida como uma mercadoria, exigindo a ampliação da competitividade em um mercado, onde diversas cidades possuem objetivos semelhantes. Nessa busca pela venda, sobressaem-se as questões valorizadas pelo capital, tais como espaços para feiras e convenções, oficinas de assessoramento a investidores e empresários e as torres de comunicação.

Verifica-se que os projetos provenientes das propostas pensadas no planejamento estratégico, devem ser observados conforme as viabilidades existentes na escala local, na medida em que se compreendem as particularidades das possibilidades de ação dos agentes, como ação para a identificação dos significados das atividades ensejadas. Ademais, compondo as imposições à composição dos planos, assume relevo o debate da participação para construção de raciocínio sobre as práticas na atualidade.

O conjunto de debates teóricos dos plans e os desdobramentos das intervenções decorrentes destes, devem ser articulados as discussões de realidades práticas, como subsídio para a identificação dos limites e perspectivas para atividades e ações dos agentes.

\section{Plano Diretor e Intervenções Urbanas na Área Central de Teresina}

Contemplando as características do urbano em Teresina e as perspectivas para a compreensão do papel do plano diretor, verifica-se que esta possui uma área de $1.392 \mathrm{~km}^{2}$, localizada na microrregião com o mesmo nome, no Centro Norte Piauiense (IBGE, 2010). A cidade apresenta peculiaridades associadas à localização estratégica proporcionada pelo entroncamento rodoviário, exercendo influencias sobre outros municípios e/ou estados, especialmente pela oferta de serviços (Figura 1). 
Figura 1- Localização espacial de Teresina

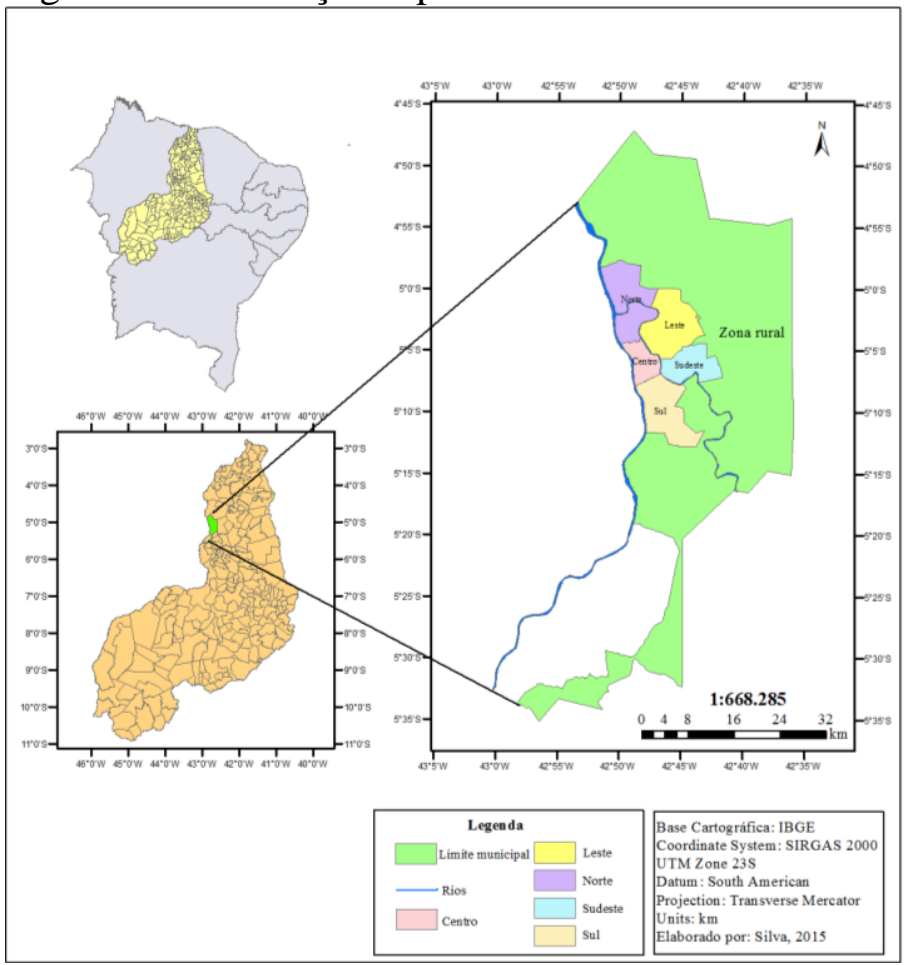

Fonte: SILVA, Silvana S., 2015.

A abordagem de Teresina na dinâmica das relações sócio-espaciais assinala a predominância do papel das atividades administrativas, comerciais e de serviços. Nesse contexto, a área central adquire relevo na concentração desse conjunto de atividades, aspecto que remete a constituição inicial das quadras em tabuleiros de xadrez que guardavam toda a dinamicidade da vida na cidade, após a transferência da sede da capital do estado, do município de Oeiras (PI) para Teresina (CHAVES, 1998).

Nesse período, as praças assumiram papel preponderante como espaço para lazer. Entre as praças existentes, ganha ênfase a Praça Marechal Deodoro que se caracterizava pela presença de cercas em seu entorno, mas também por ser local de descanso e encontro. 
Discorrendo sobre o papel do Largo do Amparo, Melo e Costa (2012) observam que nesse espaço foi edificada a Igreja de Nossa Senhora do Amparo, servindo como referência para o traçado das quadras, guardando em seu entorno edifícios simbólicos. Na abordagem das edificações localizadas no entorno da praça, Tito Filho (1974) afirma que o Mercado Central, denominado Mercadão ou Mercado Velho se destacava pela variedade de produtos vendidos.

Nos desdobramentos das modificações foram vivenciadas modificações nas formas e ritmos das práticas da área central. Anjos e Soares (2010) ressaltam o contexto vivenciado pelo Mercado central nas décadas de 1970 e início dos anos 1980, quando a predominância da degradação da estrutura física, associada aos problemas econômicos do período, incentivaram os comerciantes na busca por alternativas, sobressaindo-se a ocupação das vias, momento no qual o comércio ambulante ganha ênfase nas ruas e entorno das praças.

Com a ampliação no número de ambulantes nas ruas e praças, diversos debates passaram a envolver a busca pelo planejamento e reordenamento de usos na área central. Nesse sentido Melo (2002) enfatiza a composição do Fórum Sobre o Centro da Cidade de Teresina em 1989, que permitiu as discussões das questões relativas à infraestrutura. Destacase ainda o Fórum de Revitalização do Centro de Teresina, liderado pela Câmara dos Dirigentes Lojistas (CDL) em 1997 para reivindicar o início das ações de revitalização. Já em 2000, foi desenvolvido pela Secretaria Municipal de Planejamento (SEMPLAN) o Plano de Ações para o Centro, cuja ênfase foi representada pela necessidade de alternativas para os ambulantes nas ruas. No entanto o número de ambulantes verificou crescimento. Essa realidade concorreu para a inserção da área central como tema nos debates do Plano Diretor da cidade.

Definido como Plano Diretor, a Agenda 2015, Lei n 3.558/2006 assume na prática a proposição de desenvolvimento das exigências impostas pela Agenda 21 que representou um planejamento estratégico. A construção do plano para Teresina envolveu a existência de contradições. Assim, Lima (2012) observa que embora o Plano Diretor fosse obrigatório pelas deliberações dos novos princípios constitucionais, Teresina ainda era ordenada pela Legislação de 1988 que não correspondia às reivindicações decorrentes das transformações resultantes da expansão urbana. Somente em agosto de 2001 foi iniciada a convocação da sociedade e se instalou o Congresso da Cidade, para elaboração da Agenda 2015.

A abordagem da área central o âmbito da Agenda 2015, demonstrou que as características instaladas foram entendidas como propiciadoras de uma situação caótica, 
mediada pela presença de vendedores ambulantes, dos problemas no tráfego e na segurança. Além do exercício de carga e descarga no comércio atacadista, degradação de praças, monumentos e edifícios, poluição sonora e visual, construção de estacionamentos, mediante à demolição de importantes exemplares do patrimônio arquitetônico. Esses contextos foram associados à ausência de Legislação para o Centro e redução de investimentos (TERESINA, 2002).

Partindo dos fatores considerados negativos para a dinâmica da área central, pensou-se um “Cenário Desejável” mediado pela execução de revitalização, impulsionada pela associação entre iniciativas público-privadas. Nessa proposta, o setor comercial deveria guardar traços de limpeza, segurança, organização e dinamismo. Além disso, deveriam ser observadas ações para a valorização do patrimônio histórico e as melhorias no tráfego (TERESINA, 2002).

As observações expõem as características das conjunturas que integraram os debates em torno das demandas, gerando cenários que permitiram a elaboração dos projetos preestabelecidos para a área central (Figura 2).

Figura 2 - Projetos pensados para intervenções na área central de Teresina

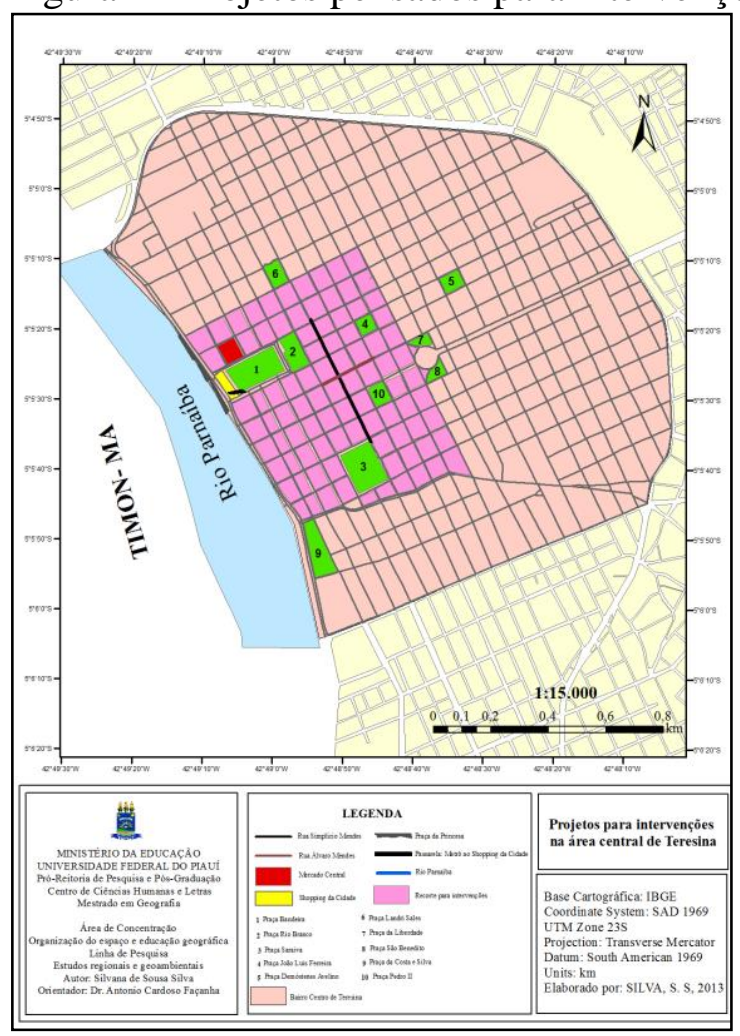

Fonte: SILVA, Silvana. S, 2014. Adaptado de Teresina (2002) e Dias (2006). 
Silvana de Sousa Silva; Antonio Cardoso Façanha

A leitura da figura 2 sinaliza que o diagnóstico realizado em torno das necessidades da área central foi integrado pelo levantamento da realidade inicial. São expostas indicações do reconhecimento da importância de projetos direcionados, para proposições da gestão compartilhada entre associações, compatibilizada com a revisão de Legislação, consecução de campanhas, com vistas à construção de conhecimentos sobre o papel da área central, além das articulações interinstitucionais.

Constata-se também a busca pelo reordenamento do comércio informal, para o fortalecimento das atividades dos lojistas, além das modificações nas direções do tráfego de veículos em algumas ruas, para favorecer a fluidez no trânsito. Além disso, são encontradas propostas para manutenção das formas que integram o patrimônio histórico-cultural, das praças e do Mercado Central, além de intervenções nas margens do rio Parnaíba, mediada pela construção de praças e a remoção dos vendedores informais (Figura 3).

Figura 3- Mosaico representando o comércio informal (A) e as intervenções efetivadas na área central (B, C, D).
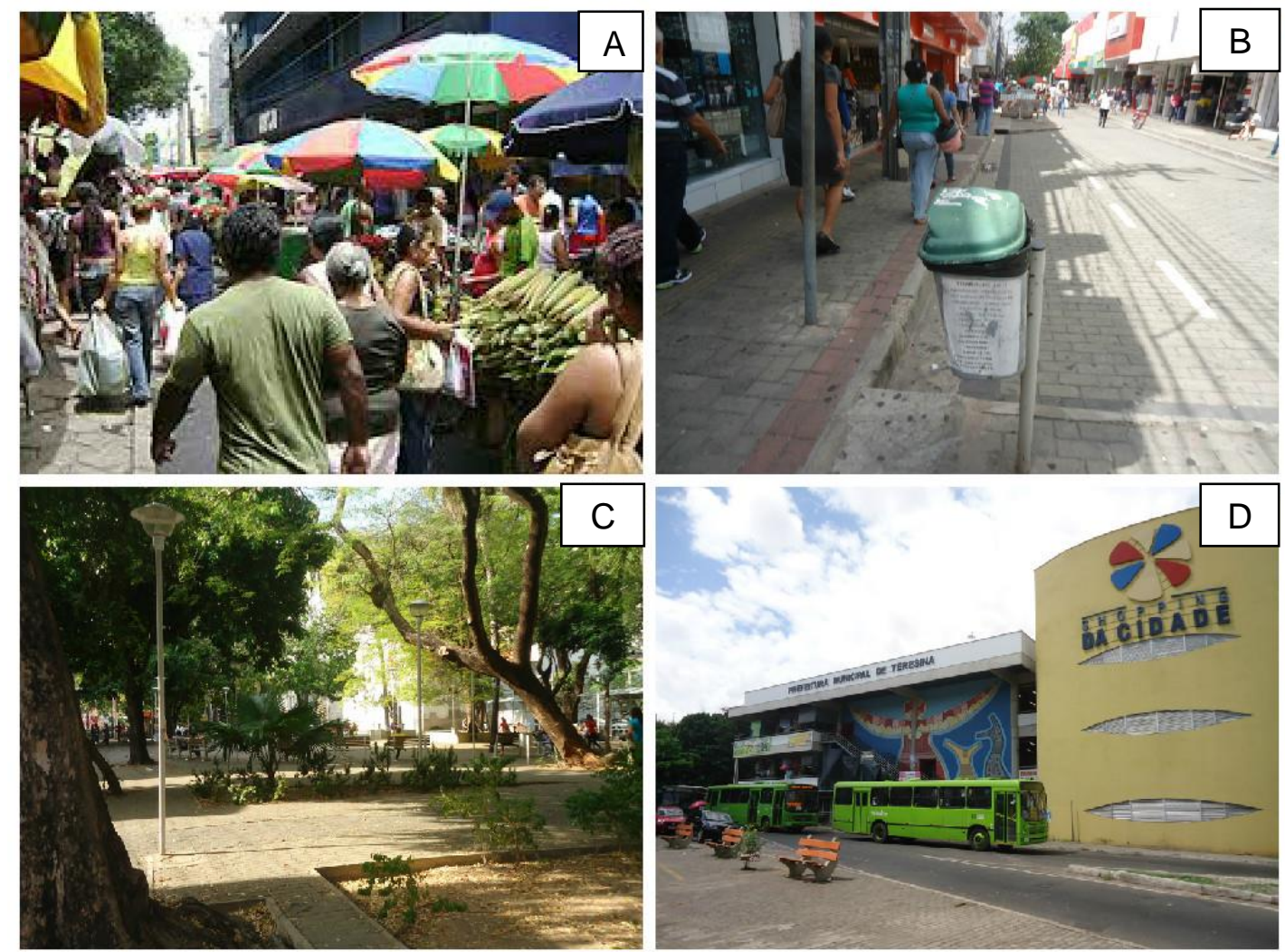

Fonte: Bacelar, 2008 (A) e Silva, 2014 (B, C, D).

A figura 3 revela diferentes faces da utilização das ruas da área central de Teresina pelas atividades do comércio informal (A) e as principais intervenções efetivadas (B, C, D), 
correspondendo à remoção dos vendedores ambulantes da ruas, intervenções na Praça Rio Branco, objetivando o resgate de características arquitetônicas e a construção de uma edificação destinada os vendedores ambulantes, respectivamente. A abordagem das intervenções, no entanto, exige a articulação com o papel exercido para os agentes e a constituição dos processos decorrentes das ações.

\section{Intervenções Urbanas na Área Central de Teresina (PI) Sob a Ótica dos Agentes}

As observações das realidades constituídas na área central revelam que os processos configurados na área central, geram exigências de aspectos que não se restringiam às questões físico-territoriais, mas também englobavam as características sócio-espaciais que convergiam para a necessidade de um Plano Diretor que adotasse perspectivas abrangentes, considerado os limites e as possibilidades de ação.

A existência de intervenções não efetivadas ou ainda a realização parcial, foi atribuída, conforme a PMT, às questões de

[...] prioridade política, controle social (que faltou), quando elencamos os projetos da Agenda 2015, o poder público tinha a relação das necessidades, mas a ONG que deveria ser criada não foi, as pessoas que participaram, a sociedade civil, associações, o movimento de base. Os movimentos sociais tem que se organizarem, fazer uma associação do bairro centro e através da organização ter uma representação e cobrarem dos atores. Os que se organizaram como os vendedores ambulantes, obtiveram resultados, os lojistas que se mobilizaram, o que não aconteceu é por que não teve uma cobrança por parte daqueles que queriam, o mercado tá acontecendo. As praças poderia ter tido mais participação, mas os moradores devem se posicionar, sem o controle de uma $\mathrm{ONG}$ as coisas não andam.

Deste modo, no trabalho com os desdobramentos das intervenções na área central, alguns caminhos foram desenhados. Nesse percurso, durante a formação do projeto para remoção, a PMT iniciou nos anos de 2005 e 2006 o cadastro de todos os vendedores que atuavam nas ruas da área central e seriam transferidos para a edificação, denominada Shopping da Cidade, localizada na área central, possuindo dois pavimentos.

A ampliação da investigação com representantes dos agentes que integraram esse processo demonstra, a partir dos contatos com a AMESCI, que as intervenções da Agenda 2015 apresentam significado relacionado a modificações no Centro de Teresina, nesse percurso muitas pessoas não se adaptaram e em alguns exemplos entraram em depressão. No 
entanto, hoje após quatro anos de instalação no Shopping da Cidade, pode-se afirmar que a adaptação é maior.

Durante a transferência, alguns ambulantes colocaram suas próprias lojas e se deslocaram para outras áreas da cidade, outros preferiram ficar viajando para vender as mercadorias em feiras. Foi muito difícil no início, para adaptação aos boxes, pois na rua mesmo com a chuva, o sol, existia o sentimento de liberdade (AMESCI, 2013).

Quando observadas as vendas, verifica-se que houve um aumento no primeiro ano, pois o número de pessoas que buscava conhecer o Shopping da Cidade era muito grande, no entanto as vendas diminuíram após esse período. Ainda abordando as demandas dos fluxos das vendas, destaca-se em muitos casos foi necessário mudar as mercadorias para atender as características do novo público (AMESCI, 2013).

Observando os principais problemas, pode ser destacado que existem muitas pessoas que não se adaptaram a estrutura do Shopping da Cidade, tornando-se comum acontecer brigas entre vizinhos de boxes. Além da ausência de efetivação de propostas de projetos como a passarela que ligaria a estação do metrô ao Shopping da Cidade, contribuindo para aumentar as vendas e a construção de creche para os filhos dos comodatários (AMESCI, 2013).

É possível perceber que o processo de intervenção e remoção dos ambulantes das ruas gerou dinâmicas diversas, entre elas o abandono da área central, como espaço para atuação de alguns vendedores ambulantes.

Destarte, o trabalho com os ambulantes transferidos para Shopping da Cidade, revelou que apenas $38 \%$ do universo amostral, participaram de reuniões durante a elaboração da Agenda 2015. Compondo as características dos microempreendedores, constatou-se o deslocamento cotidiano de outros bairros das diferentes zonas da cidade e do município maranhense de Timon limítrofe à Teresina, para desenvolvimento das atividades na área central de Teresina, corroborando com as observações de Corrêa (2005), Tourinho (2006) e Dantas (1997), ao destacarem o papel de atratividade exercido pela área central.

A associação entre as intervenções para o deslocamento para o Shopping da Cidade e as influências no fluxo de vendas, demonstrou que para $18 \%$ dos pesquisados, as vendas sofreram aumento, para $37 \%$ elas permaneceram iguais e para $45 \%$ elas diminuíram. A leitura dos percentuais associados às observações diretas demonstra que a redução das vendas é indicada especialmente pelos vendedores que não estão instalados no térreo. 
A permanência no percentual de vendas em detrimento do acréscimo, em alguns exemplos foi atribuída à própria dinâmica que compõe a atividade comercial. Dessa maneira, a relação entre o acréscimo/redução não está ligada ao local de comercialização, mas ao período do ano. Como exemplo, observa-se que nos momentos antecedentes de datas comemorativas, geralmente as vendas verificam expressivo acréscimo. Ademais, as observações demonstram que a ausência de diversificação de mercadorias em alguns boxes, pode atuar motivando os baixos índices de vendas.

Complementando a análise das relações das vendas, $38 \%$ afirmaram que o perfil dos clientes mudou após a transferência para o Shopping da Cidade. Por outro lado, $56 \%$ dos microempreendedores não modificaram as mercadorias e $46 \%$ sentiu a necessidade de alterações no tipo de produtos, visando a atender as características compostas pela diversificação de consumidores que estabeleceram novas exigências, além de ampliação do volume de mercadorias.

A multiplicidade na origem dos consumidores de produtos ofertados pelas atividades desenvolvidas na área central, foi verificada também pelos lojistas, na medida em que para 93\% dos pesquisados existe um contínuo fluxo de clientes provenientes de outros municípios.

Ampliando as perspectivas para debates das realidades constituídas, após as intervenções decorrentes das propostas da Agenda 2015, na análise com os lojistas 64\% afirmaram que os ambulantes nas ruas representavam entraves para os estabelecimentos comerciais. Além disso, para 43\%, o número de consumidores aumentou após as intervenções, a participação nas discussões, apenas $21 \%$ integraram as reuniões durante os Seminários.

No levantamento de características das intervenções para os lojistas, verificou-se que para 79\% o resultado das intervenções nas Ruas Simplício Mendes e Álvaro Mendes podem ser considerados bons e para $21 \%$ ótimos. Entretanto, $71 \%$ revelaram que a área central ainda necessita de intervenções como segurança, proibição de circulação de carros nas vias centrais, intervenções em calçadas, existência de fiscalização e controle da poluição sonora.

Dessa forma, é possível verificar que o conjunto de intervenções envolveu atuação diferenciada dos agentes, concorrendo para a obtenção de resultados que não atendem às exigências da totalidade dos diretamente envolvidos, sobressaindo-se a concretização de projetos que permitiam o atendimento às demandas dos lojistas. As realidades configuradas, 
reiteram as abordagens de Lacerda et. al (2005) e Maricato (2012), ao trabalharem com os limites da das práticas dos planos diretores.

\section{Conclusão}

A dinamicidade que caracteriza as relações desenvolvidas no espaço urbano é composta por processos que refletem, dentre outros, a atuação dos diferentes agentes sociais, mediados pela busca da contemplação de objetivos que se originam nos anseios diários.

Diante dos quadros que envolvem o planejamento urbano em Teresina, com ênfase para o documento adotado como plano diretor-Agenda 2015, foram realizadas abordagens das contradições na elaboração do referido plano, além das observações acerca da realidade constituída, a partir do reconhecimento dos processos efetivamente ensejados e daqueles não realizados, na área central.

As análises empíricas demonstraram que as intervenções urbanas realizadas a partir das disposições da Agenda 2015 atuaram preponderantemente para o atendimento dos objetivos estabelecidos por determinados agentes, quando constata-se as ações para a remoção de barracas e melhorias nas ruas como recurso frequentemente citado como fundamental para a melhoria das vendas das lojas na área central.

Do exposto, verificou-se que o conjunto de ações corresponde a intervenções parciais que não contemplaram de forma articulada às demandas encontradas na área central, atuando em um primeiro momento para esconder problemas e fundamentar afirmações positivas sobre o papel desempenhado pela construção dos planos.

Ainda integrando as realidades configuradas a partir da Agenda 2015 na área central, a abordagem com os lojistas apontou a reiteração da associação dos ambulantes aos entraves para as vendas, e a aprovação das intervenções realizadas, constituindo ressalvas apenas os aspectos cuja concretização auxiliaria na ampliação dos ganhos com as atividades.

Consoante o evidenciado, quando considerada a Agenda 2015, as observações reiteram as abordagens críticas da adoção de modelos fundamentados em outros planos, concorrendo para a pequena ou ausente consideração das relações estabelecidas com os demais municípios ou estados. Quando analisados os exemplos em Teresina, essas relações apresentam frequência que adquirem ênfase quando contemplada a área central.

\section{Referências}


ANJOS, Claudiana C. dos; SOARES, Rafaela R.. Trajetória da Praça Marechal Deodoro. In: RÊGO, Ana R.; MENDES, Cecília; QUEIROZ, Teresinha. Piauí: história, cultura e patrimônio. Teresina: Instituto Camilo Filho, 2010. p.125-142.

BACELAR, Allisson. Comércio informal no Centro de Teresina. 2008. 1 fotografia, color. Disponível em: $<$ http://www.humanasaude.com.br/novo/materias/2/com-rcio-informal-refor-aa-necessidade-de-revitaliza-o-do-centro-de-teresina_5143.html>. Acesso em: 13 out. 2012.

BRASIL. Constituição (1988). Constituição da República Federativa do Brasil . Brasília, 5 out. 1988.

Lei $\mathrm{n}^{\circ} 10.257$, de 10 de junho de 2001. Regulamenta os arts. 182 e 183 da

Constituição Federal, estabelece diretrizes gerais da política urbana e dá outras providências.

Diário Oficial [da] República Federativa do Brasil, Poder Executivo, Brasília, DF, 10 jun. 2001a. Disponível em: < http://www.planalto.gov.br/ccivil_03/leis/LEIS_2001/L10257.htm>. Acesso em: 03 nov. 2012.

CASTELLS, Manuel; BORJA, Jordi. As cidades como atores políticos. Tradução de Omar Ribeiro Thomaz. Novos Estudos. São Paulo, n.45, 1996. Disponível em:< http://www.acsmce.com.br/wp-content/uploads/2012/10/AS-CIDADES-COMO-ATORESPOL\%C3\%8DTICOS.pdf.>. Acesso em: 15 jun. 2013.

CHAVES, Monsenhor. Obra completa. Teresina: Fundação Cultural Monsenhor Chaves, 1998.

CORRÊA, Roberto L. Trajetórias geográficas. Rio de Janeiro: Bertrand Brasil, 2005.

DIAS, Cid de C. Piauí projetos estruturantes. Teresina: Alínea, 2006.

INSTITUTO BRASILEIRO DE GEOGRAFIA E ESTATÍSTICA. Censo demográfico-

População. 2010. Disponível em:< http://censo2010.ibge.gov.br/>. Acesso em: 12 set. 2012.

LIMA, Antonia J. de. Planos diretores e os dilemas da governança urbana no Brasil. Textos e contextos. Porto Alegre, v. 11, n. 2, p. 362-375, 2012. Disponível em:

<http://revistaseletronicas.pucrs.br/ojs/index.php/fass/article/view/11837/8643>. Acesso em: 30 jun. 2013.

MELO, Alcília A. de A.. A revitalização do centro de Teresina. Scientia et Spes, Instituto Camilo Filho, Teresina, ano 1, n. 2, p. 35-48, 2002.

MELO, Alcília A. de A; COSTA, Júlio A. de A. O centro histórico de Teresina: intervenções contemporâneas e conflitos na paisagem urbana. In: SEMINÁRIO PAISAJES CULTURALES. 2. 2012, Montevidéu. Anais eletrônicos...Montevidéu: Udelar/UPC.

Disponível em: <http//: www.conpadre.org/conpadritos/c11-2012/art_31.pdf>. Acesso em: 05 jul. 2013.

SILVA, José. B. Vivendo a cidade: o caso de Fortaleza. In: VASCONCELOS, José G.; ADAD, Shara J. H. C. (Org.). Coisas de Cidade. Fortaleza: Editora UFC, 2005. p. 7-24. 
SOUZA, Marcelo L. de; RODRIGUES, Glauco B. Planejamento urbano e ativismos sociais. São Paulo: UNESP, 2004.

SOUZA, Marcelo L. de. Mudar a cidade: uma introdução crítica ao planejamento e à gestão urbanos.4. ed. Rio de Janeiro: Bertrand Brasil, 2006.

SPÓSITO, Maria E. B. Segregação sócioespacial e centralidade urbana. In:

VASCONCELOS, Pedro de A.; CORRÊA, Roberto L.; PITAUDI, Silvana M. A cidade contemporânea: segregação espacial. São Paulo: Contexto, 2013. p. 61-94.

TERESINA. Lei Complementar $n^{\circ} 3.560$, de 20 de outubro de 2006. Define as diretrizes para o uso do solo urbano do Município e dá outras providências. Diário Oficial [do] Município, Teresina, PI, 20 out. 2006. Disponível em: <http://www.teresina-pigov.com.br/media/uploads/documento/2012/03/Lei_n_3.560_de_20.10.2006__USO_DO_SOLO.pdf.>. Acesso em: 02 jan. 2013.

Lei $\mathrm{n}^{\mathrm{o}} 3.558$, de 20 de outubro de 2006. Reinstitui o Plano Diretor de Teresina, denominado Plano de Desenvolvimento Sustentável - Teresina Agenda 2015, e dá outras providências. Diário Oficial [do] Município, Teresina, PI, 20 out. 2006. Disponível em: <http: www.teresina.pi.gov.br/dom/doc_diario/DOM1124-1-27102006.pdf> Acesso em: 14 mar. 2013.

Secretaria Municipal de Planejamento e Coordenação Geral. Teresina: Agenda 2015 - Plano de Desenvolvimento Sustentável. Teresina, 2002.

. Secretaria Municipal de Planejamento e Coordenação Geral. Entrevista, 2013.

TOURINHO, Andréa de O. Centro e centralidade: uma questão recente. In: OLIVEIRA, Ariovaldo U.; CARLOS, Ana F. A. Geografia das Metrópoles. São Paulo: Contexto, 2006. p. 227-299.

ULTRAMARI, Clovis; REZENDE, Denis A. Planejamento estratégico e Planos Diretores Municipais: referenciais e bases de aplicação. Revista de Administração Contemporânea. Curitiba, v.12, n.3, p. 1-15, 2008. Disponivel em:<http://dx.doi.org/10.1590/S141565552008000300006> Acesso em: 20 jun. 2013.

VAINER, Carlos. Pátria, empresa e mercadoria: notas sobre a estratégia discursiva do Planejamento Estratégico Urbano. In: ARANTES, Otília; VAINER, Carlos; MARICATO, Ermínia. A cidade do pensamento único: desmanchando consensos. Petrópolis, RJ: Vozes, 2000. p. 75-103.

VILLAÇA, Flávio. Espaço intraurbano no Brasil. São Paulo: Studio Nobel, 2001. 